\title{
Cultural Characteristics of Traditional Architecture and Scenic Architecture in the Online Games
}

\author{
Yingbo Du ${ }^{1}$, , Guidan $\mathrm{Du}^{2}$ \\ ${ }^{1}$ Department of Art and Crafts, Changchun University, Changchun, China \\ ${ }^{2}$ Department of Mass Communication, Jilin Agricultural University, Changchun, China \\ Email address: \\ Duyucong1022@163.com (Yingbo Du),duguidan@126.com (Guidan Du) \\ *Corresponding author
}

\section{To cite this article:}

Yingbo Du, Guidan Du. Cultural Characteristics of Traditional Architecture and Scenic Architecture in the Online Games. Humanities and Social Sciences. Vol. 4, No. 4, 2016, pp. 113-118. doi: 10.11648/j.hss.20160404.15

Received: June 11, 2016; Accepted: July 9, 2016; Published: July 12, 2016

\begin{abstract}
Through several generations of development and evolution, online games have penetrated into every corner of people's lives and formed a new kind of consumption culture, thus they are likely to be not only required, but essential for the folk's daily life and broaden the horizon and knowledge of the players at the same time. Architecture scene in the online games is an important occasion and environment for the activities and performance of the game characters. Architecture scene includes time, location, and space, and it helps to show the historical background and the geographical environment from multiple perspectives. More importantly, it helps to show the relative architecture culture style and the architecture characteristics of the times. In online games' virtual world, exquisite architecture scene can not only set off the competition atmosphere, bring the players into the games' plot quickly, but also make the cultural connotation and the cultural emotion that the makers want to convey in the games sensed visually by the players. Online games should be treated rationally, because it is not only a media of entertainment but also a media of cultural transmission. With the emergence and popularity of many online games based on Chinese stories, we should pay more attention to the function of transmission of the online games.
\end{abstract}

Keywords: Online Games Scene, Traditional Architecture, Scenic Architecture, Culture Characteristic

\section{Introduction}

As a new cultural product, the cultural transmission function of contemporary online games is increasingly apparent. Generally, online games contain the understanding of the makers and players towards character, image, music, aesthetics, and world view. In a narrow sense, it includes multiple factors belonging to the games, for example, architecture, costume, literature and so on. Through several generations of development and evolution, online games have penetrated into every corner of people's lives, form a new kind of consumption culture, become a necessity of the folk's daily life and broaden the horizon and knowledge of the players at the same time [1-2].

Architecture scene in the online games is an important occasion and environment for the activities and performance of the game characters. Architecture scene includes time, location, and space, and it helps to show the historical background and the geographical environment from multiple perspectives. More importantly, it helps to show the relative architecture culture style and the architecture characteristics of the times.

In online games' virtual world, exquisite architecture scene can not only set off the competition atmosphere, bring the players into the games' plot quickly, but also make the cultural connotation and the cultural emotion that the makers want to convey in the games sensed visually by the players. Online games should be viewed rationally, because it is not only a media of entertainment but also a media of cultural transmission [3-4]. Architecture scene includes time, location, and space, and it helps to show the historical background and the geographical environment from multiple perspectives.

\section{Importance of Chinese Architecture in Games}

With the emergence and popularity of many online games 
based on Chinese stories, the function of transmission of the online games has attracted much attention.

Many excellent contemporary online games are created and revised on the basis of Chinese historical stories, myth and legends, for example, Peach Blossom Spring, The Enchanting Shadow, which belong to the fantastic category; For the historical category, there are The Three Kingdoms and The Legend Of Yue Fei; for martial art category, there is Dragon Oath; for the mythical, there are The West Odyssey, Havoc In Heaven. All of these games use traditional Chinese architecture style and architecture culture for reference without exception, including the above-mentioned online games - Peach Blossom Spring, Three Kingdoms and Havoc In Heaven as shown in Figure 1.

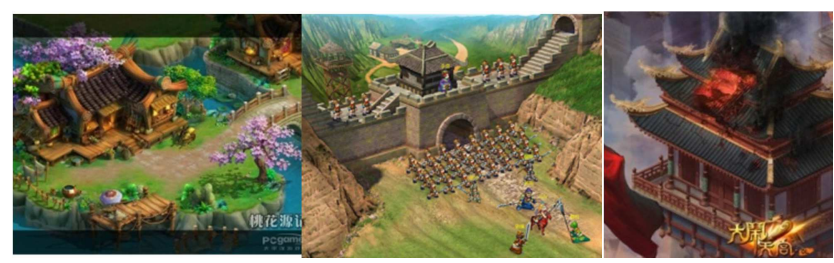

Figure 1. Pictures of online games such as Peach Blossom Spring, Three Kingdoms and Havoc In Heaven.

A local-ethic cultural atmosphere is created in game architecture scene by using Chinese architecture style, elements and special cultural characteristic. The players can experience fabulous traditional Chinese architecture scene, at the same time get a deeper understanding of national culture.

Traditional Chinese culture is not shown only in modern architecture, and it is also shown in traditional architecture. Moreover the online games should be used to transmit more traditional culture information, for example, traditional costume, traditional weapon, and traditional tools.

Traditional Chinese architecture stands out in the world's architecture system with its' unique characteristics. It contains full-bodied oriental culture, different forms of roofs, delicate layout, decoration, inscribed board and couplet, all of which have different cultural meaning, and symbolize different social meaning and hierarchy system. In figure 2, classical halls with typically traditional Chinese culture are designed to be integrating into online games. The object is to explore the links between cultures, game's background and player's personality.

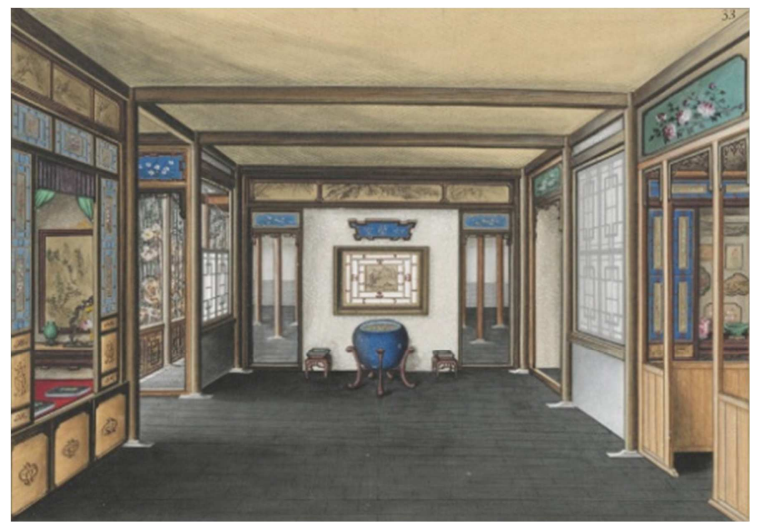

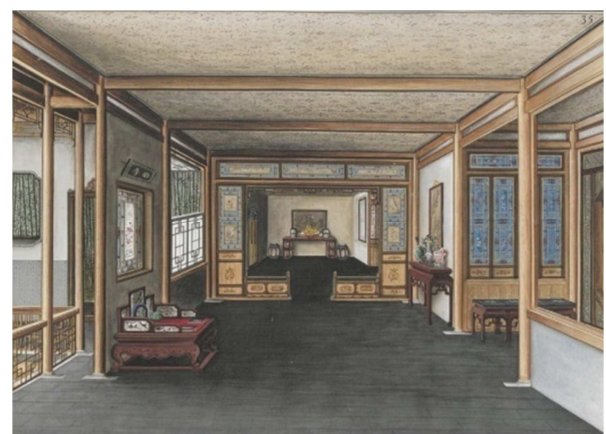

Figure 2. Typically traditional Chinese halls for online games.

Traditional Chinese architecture contains colorful Chinese cultural connotation, more than architecture itself, so Chinese architecture have a lot more needed to be read.

\section{Culture Embodied in Architecture Structure}

Ancient Chinese architecture is mainly made of wood, in which pier and beam construction plays a crucial role [5]. Usually there is raised-beam frame, column and tie construction, log cabin construction, among which raised-beam frame is most widely used, usually being a basic structure of a traditional Chinese house as shown schematically in Figure 3.

Bracket structure is the most important trait of ancient Chinese architecture, and it plays a role of carrying the extension of the roof, even in decline, it still have a function of decoration. The trait of bracket structure is its' structural uniqueness, solemn majesty, luxury, so it is mainly used in palace and temple, and the palatial architecture in the games based on Chinese stories adopt this structure most of the time.

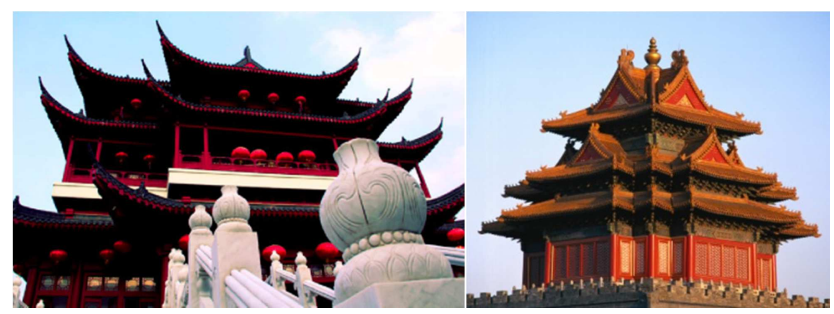

Figure 3. Typically traditional Chinese halls for online games.

Ancient Chinese individual building usually has a sharp appearance, and plane form includes square, rectangle, hexagon, octagons. An individual building has stylobate, wall and roof. Stylobate could have single layer or multiple layers, and the door, the window, the pillar is very flexible because of its' wooden structure, and pillars are greatly used in architecture. The roof forms are variable and meaningful, for example, the earlier gable and hip roof, overhanging gable roof, flush gable roof, single eaves hip roof, double eaves hip roof, pyramidal roof, Octagonal pavilion, and the later joint roof, single pitch roof, long flat, cross slope, jar top, arch roof, the vault top, and many other forms. Thereby, some games 
fabricate a variety of ancient Chinese architectures to augment the realistic and immersive feelings, for example as shown in Figure 4.

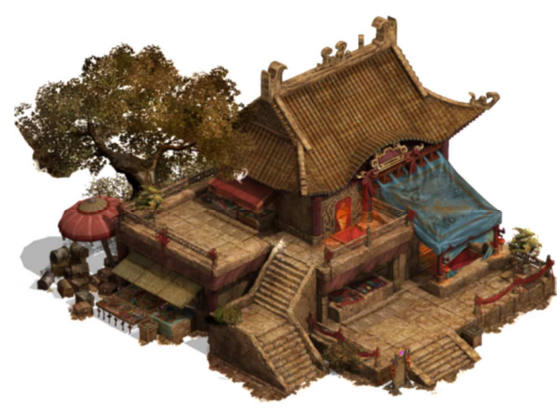

Figure 4. An ancient Chinese architecture for games (cited from Ancient Chinese architecture).

Augment reality in online games should be compromising solution of architectures in facts and in arts. Two kinds of ancient Chinese architectures are created artificially and artistically and shown in Figure 5 and Figure 6, respectively. These two cases are full of ancient Chinese characteristics.

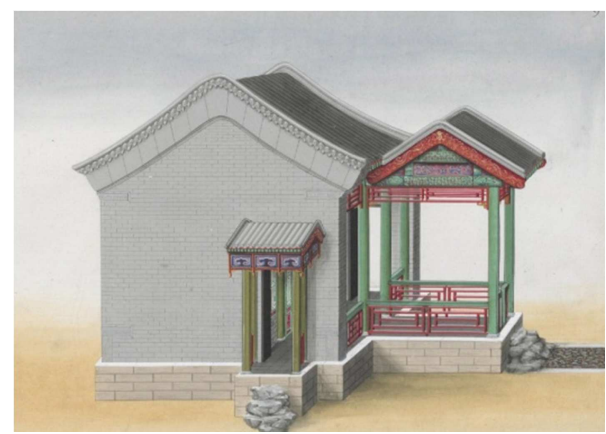

Figure 5. The artistic front gate created for online games.

Every form has its special connotation, such as the combination of gable and hip roof and the hip roof with a flush gable roof, the upper side uses flush gable roof, and the two roofs are perpendicular, form a triangle with the front and back slopes. It lower side extends to the eave, and the house has one main ridge, four vertical ridges, four angle ridge, commonly known as nine ridge temple.

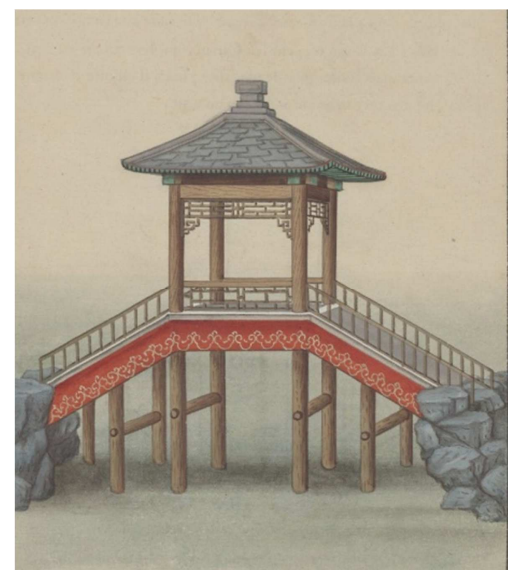

Figure 6. The artistic pavilioncreated for online games.
For ancient Chinese architecture in online games, designers like to use multiple gable and hip roof, double eaves, multiple base stations bar, and polygonal pavilion to create luxurious and dreamlike palace cluster and individual building. For example, the haven palace, temples and pavilions tend to have structures like multiple gables and hip roof, multiple hip roof and pavilion. Figure 7 is a typical case, which includes several ancient Chinese architectures.

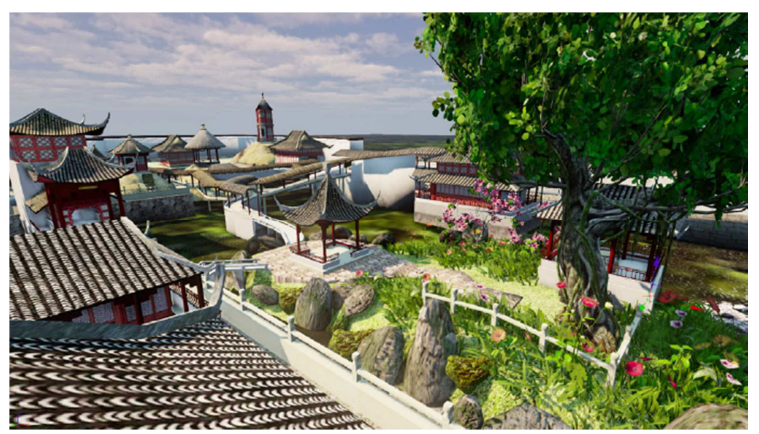

Figure 7. The artistic pagoda created for online games.

Through designers' revision and imagination, cultural characteristics are shown of ancient Chinese architecture, a wonderland and atmosphere of architecture scene is created, and players' imagination is also extended. Games could bring people entertainment, but optical elements of a game should show cultural information. Optical expression of traditional architecture forms gives players a sense of beauty and at the same time reflects cultural characteristics of national architecture. In figure 8 , the ancient Chinese pavilion is combined with modern screw architecture, which could be an attractive scene for game players.

Rigorous design, rational understanding, precise convey are strict annotation on traditional culture of the designers. Through long time amusement, accumulation and sense, players more or less get to know spirit and connotation contained in the traditional Chinese architecture. So the role of cultural transmission of the games designers has very important practical significance.

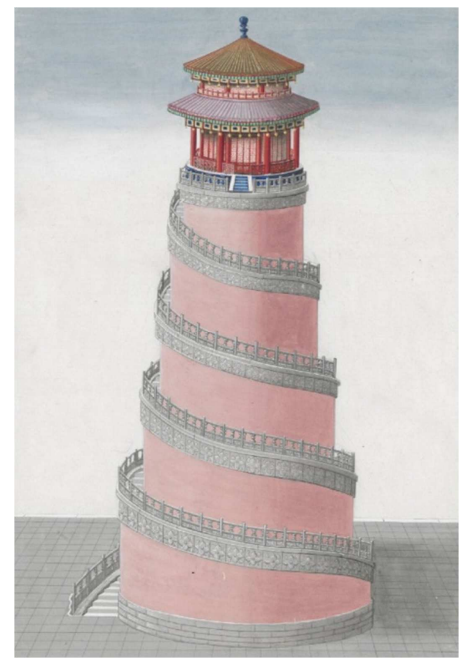

Figure 8. The artistic and imaginative pagoda. 


\section{A Culture of Combination of Three Religions}

Chinese feudal society have lasted for thousands of years, under which the values, way of life have been deeply influenced by the thought of combination of three religions.

Confucianism emphasizes courtesy, Taoism emphasizes freedom and ease, and Buddhism emphasizes inaction. These thought of the thought have been deeply embedded into the thought of our ancestors, and formed a strict ideological system.

Neatness and regularity, civil order, and symmetry of architecture all reflect moderate thinking of Confucianism. The layout of the architecture focus on a middle line, and major buildings are in the line, and minor buildings line next them on both sides. Even if a door in a game, the symmetry is necessary to reflect Chinese culture.

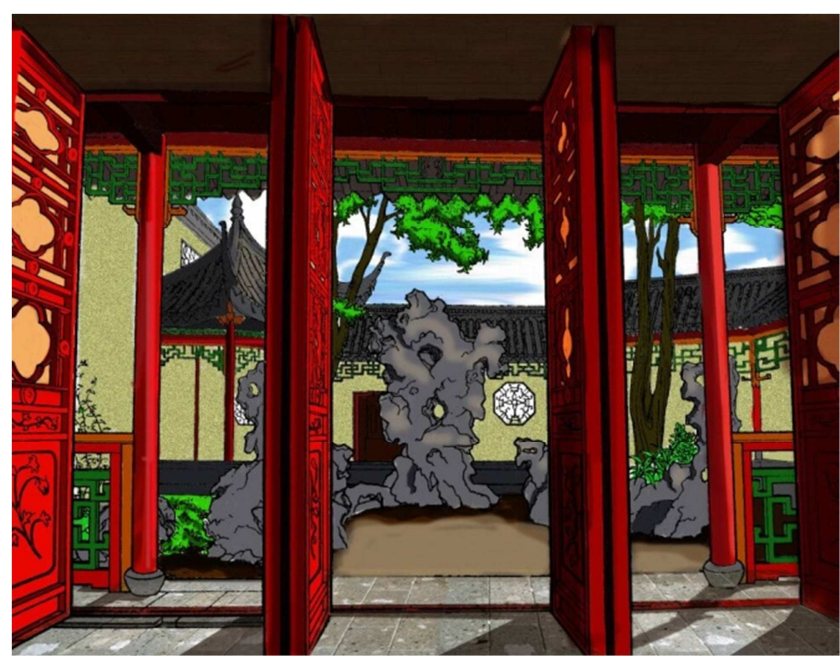

Figure 9. A door with symmetric structure.

The hierarchy is strict [6], especially rooted from ancient China's patriarchy and moral codes. This is more apparently shown in taoist temple or Yamen in China shown in Figure 10 and Figure 11.

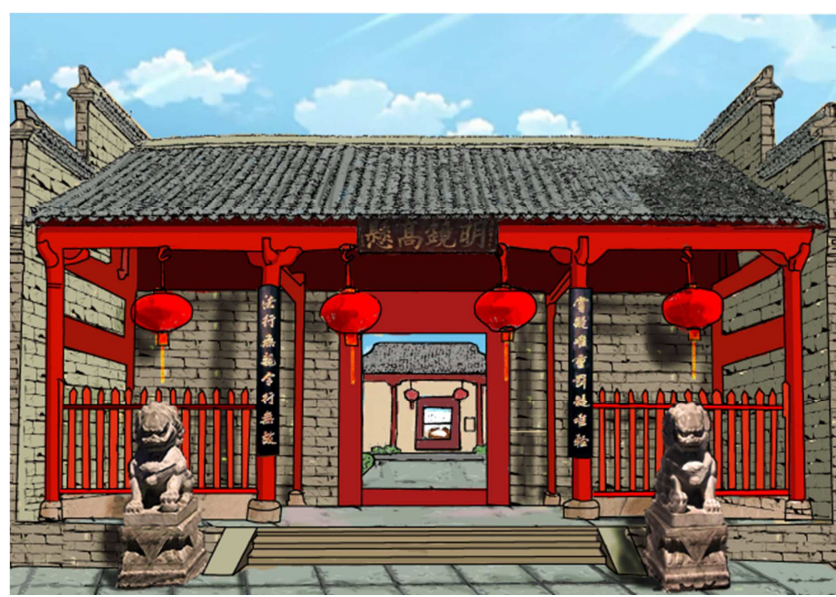

Figure 10. The front view of a Yamen.

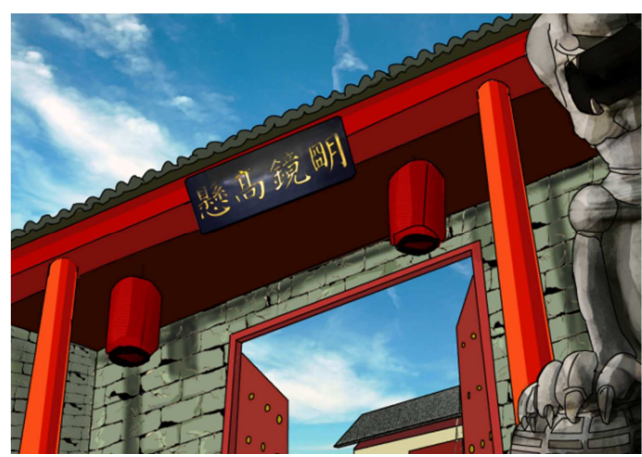

Figure 11. The door header of a Yamen.

After thousands of years development and evolution, no matter it is royal palace or temple, Taoism temple, pavilion or civil house, a kind of high uniformity of three religions has been achieved. This cultural thought has influenced not only a single building, but also has influenced the layout of the whole city and one example is that a town usually has double bell towers, confucious' temple and city god temple. Classical garden design is also a concentrated demonstration of the cultural thought of integration of three religions.

Artistic conception expression mainly focus on three aspects-running a country, god, nature. Confucianism tends to be practical, and emphasize ethics and morals, and argued to run a country with manners. The thought of Taoism focus on appreciating the nature, keeping quiet comfortable static, whose aesthetic appreciation belongs to romanticism. Buddhism pursue end, nirvana, and Taoism pursue inaction, immortality, which belongs to wonderland. The aesthetic conception, running a country, is mainly adopted by royal garden, for example, half scenery of The Old Summer Palace shows this idea. The natural aesthetic conception is reflected mainly in southern garden, such as SuZhou Garden in Figure 12.

Whereas, wonderland is mainly embodied in temple gardens and taoist temple gardens, for example, The Fairy Bridge in QingCheng Mountain, and the Soaring Rock in WuDang Mountain.

The architecture design, such as the palace design, in all kinds of contemporary online games that are based on Chinese stories takes the royal gardens, temple cluster and southern garden architecture as blue print. The fabulous pavilion and natural scene more or less reflect Chinese traditional cultural thought.

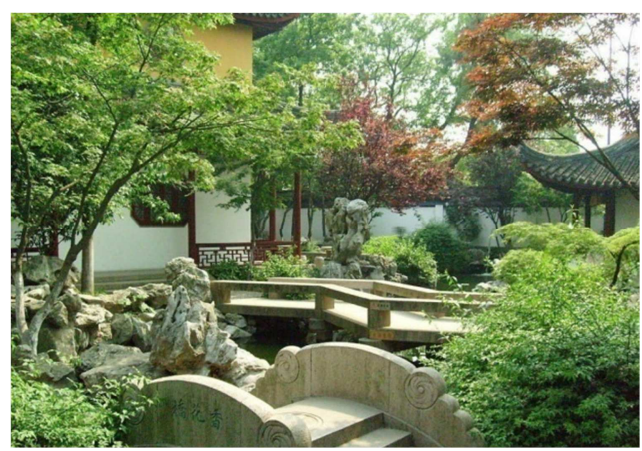

Figure 12. SuZhou Gargen. 
For example, the dimensions of the palace and the decorations are all symmetric with a middle axis, which gives people a feeling of grave and majesty. It is usual that a garden is an important site in ancient games. Therefore, an artistic garden is designed with these ancient Chinese elements in Figure 13 and Figure 14.

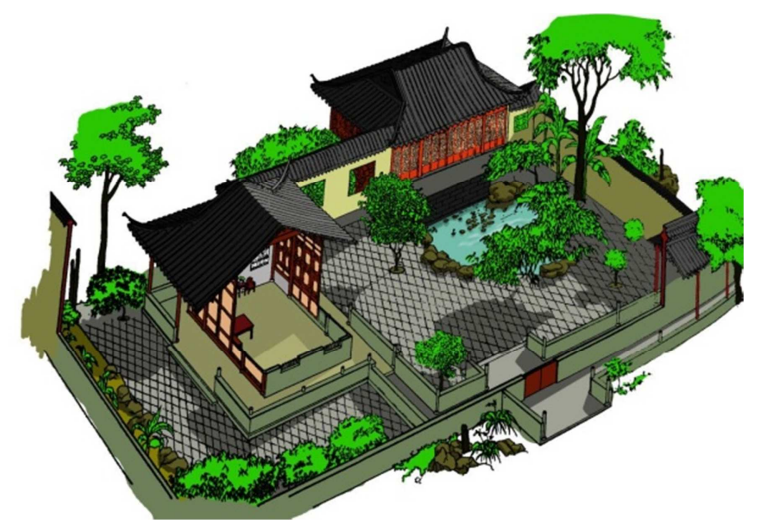

Figure 13. The artistic garden of ancient games.

The grand city, layout of the palace and the order of civil houses in The Legend OF MoXia also take the layout of traditional Chinese royal architecture cluster and town as reference. Peach Blossom Spring learns lessons from traditional garden design, whose typical characteristics are "a small bridge over the flowing stream", "The path winds along mountain ridges" and so on, all of which have demonstrated the trait of integration of nature of the southern garden architecture.

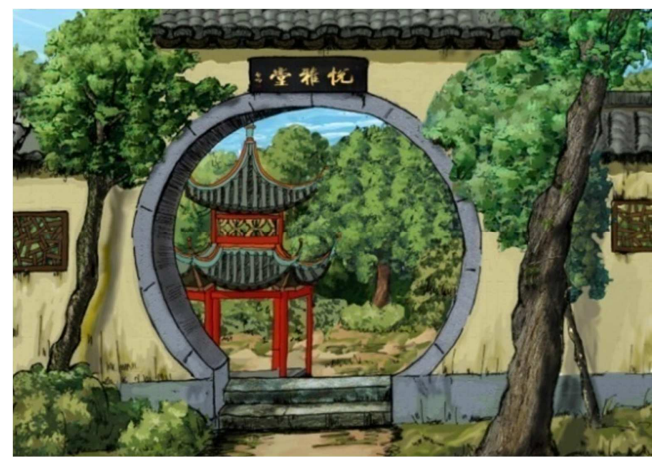

Figure 14. The arc door of an artistic garden.

\section{Culture of Metaphysics}

The way of thinking of ancient Chinese was deeply influenced by The Book of Changes, so they thought considering things in the way that Philosophy of Yi has stated would help to find something regular. It is the same in architecture. For example, ancient Chinese buildings use more wood than stones not out of technical problem, which indeed belongs to a cultural phenomenon. Personality and motivations for playing online games are very important [7], especially in the video games or online games [8-11].

In the five elements, "Wood" refers to spring, green and life, so this is used to build house for human. However, "Soil" refers to bricks and stones, "This lifetime to return no, renewable", so it is mainly used to build tomb for the dead. Ancient Chinese cultural ideas, taking Eight Tri-grams, Five Elements, Geomancy as examples, had a leading influence on ancient Chinese architecture. These are important for both rulers and folks including the height and the width of a architecture, martial choosing and locations of mountains and rivers. Figure 15 is a design example, which is a 3-D model applying in games [12].

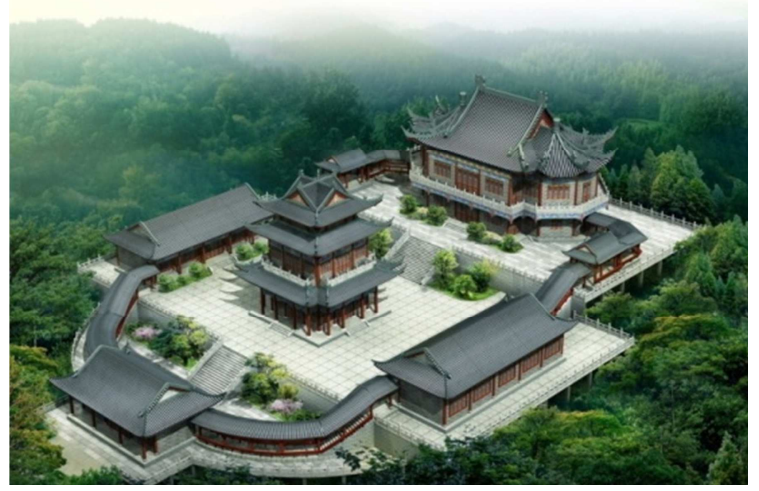

Figure 15. The architectures with mountains.

The Palace Museum is the best annotation of The Five Elements. The city longed $15 \mathrm{~km}$ along the south- north axis, in which 15 is a constant of orientation in Luo Book. The color of walls and pillars is red, because red belongs to "Fire", which means be fair and upright. The central ceiling is yellow, and this color belongs to "Soil", which in The Book Of Changes means vigorous and medium and suitable for life to grow. The ceiling of East Palace is green, which belongs to "Wood", which means vibrant, so it is suitable for the future successor of the power. According to this design consideration, the merits of symmetry and the thoughts of Philosophy of Yi are compromised to create a conceptual pavilion as shown in Figure 16.

Regulation of Yin and Yang also use Philosophy of Yi, and its' aim to achieve the state of unity of haven and man. Culture of Metaphysics may be reflected in online games' architecture scene, and designers should know about the cultural common sense. It is a problem that game industry must think about. Taking a pavilion for example, a Yin and Yang pavilion as shown in Figure 17. It has a concise and symmetric structure and the left represents Yang while the right denotes Yin.

It also should be noticed that the reflection of Yin and Yang, Five Elements is still ambiguous, not precise enough. Because Yin And Yang, Five Elements are not objective, so it need to be read properly by the industry, and only with proper use, can the connotation of traditional architecture be lifted. The outbreak of this phenomenon is also a problem the industry deed to face. Plain overlay of these elements of architecture will lead to cultural misunderstanding during transmission. Proper reading and convey of cultural information is a responsibility that the online game designers should shoulder. 


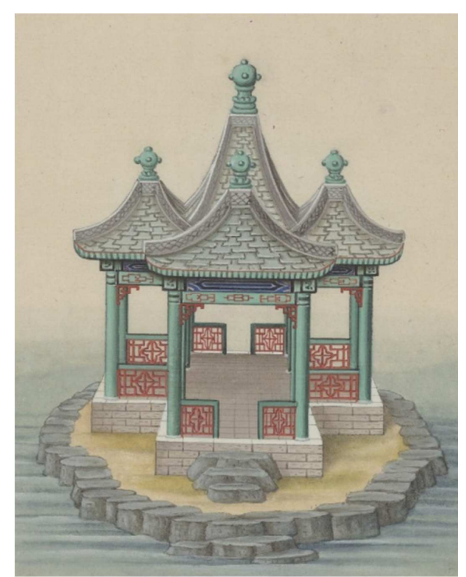

Figure 16. The conceptual pavilion.

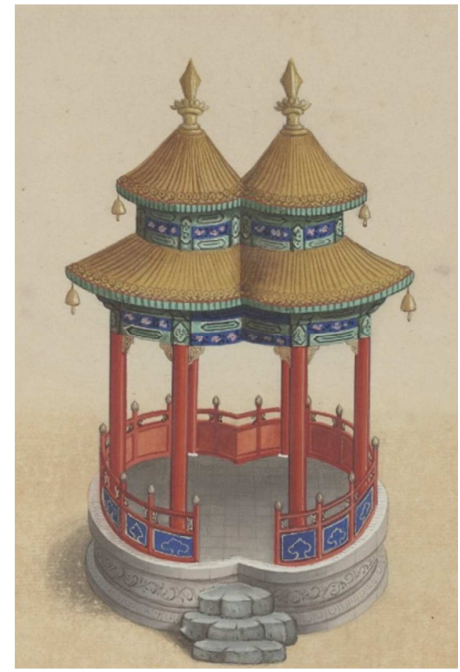

Figure 17. The Yin and Yang pavilion.

\section{Conclusion}

The popularity and openness of contemporary online games makes the new consumption culture mature day by day, and new technology makes the entertaining terminal more complete, so this is the trend of entertainment culture.

Online games are not only a media of entertainment but also a special media of cultural transmission. With the emergence and popularity of many online games based on Chinese stories, we should pay more attention to the function of transmission of the online games.

Chinese culture need to be transmitted from multiple perspectives to make Chinese more realized of ourselves and at the same time to make us understood better by the rest of the world.

\section{Acknowledgements}

This project is supported by the Research Program of the Education Department of Jilin Province (Grant No. 2014-J-B-3-21-W15)

\section{References}

[1] C. Bateman, R. Boon, 21st Century Game Design, Charles River Media, Hingham (2006)

[2] China gaming industry report (Abstract). Retrieved from $<\mathrm{http} / / /$ www.cgigc.com.cn/d/game_report_2014_brief.pdf>, (2014), accessed 18th May 2015.

[3] Chaoguang Wang, Gino Yu, "The value system characteristics of Chinese online game players,"doi:10.1016/j.entcom.2016.04.003

[4] J. Park, Y. Song, C.-I. Teng, "Exploring the links between personality traits and motivations to play online games, Cyberpsychology," Behavior, and Social Networking, 14 (12) (2011), pp. 747-751.

[5] Deng Shiyuan, Bai Junwei, "Game Scene with Chu (Ancient Place Name) Art Characteristics Produced by 3D Technology," Energy Procedia, Volume 17, Part B, 2012, pp. 1299-1303

[6] Michela Mortara, Chiara Eva Catalano, Francesco Bellotti, Giusy Fiucci, Minica Houry-Panchetti, Panagiotis Petridis, "Learning cultural heritage by serious games Review Article," Journal of Cultural Heritage, Volume 15, Issue 3, May-June 2014, pp. 318-325.

[7] S. Jeng, C.-I. Teng, "Personality and motivations for playing online games," Social Behavior and Personality, 36 (8) (2008), pp. $1053-1060$

[8] Cylor Spaulding, "Applying the devotional-promotional model to the video game "Faithful", Public Relations Review, Volume 42, Issue 2, June 2016, pp. 359-365

[9] M. E. Portman, A. Natapov, D. Fisher-Gewirtzman, "To go where no man has gone before: Virtual reality in architecture, landscape architecture and environmental planning," Computers, Environment and Urban Systems, Volume 54, November 2015, pp. 376-384

[10] Theodore John Rivers, "An introduction to the metaphysics of technology," Technology in Society, Volume 27, Issue 4, November 2005, pp. 551-574.

[11] Chris Thornhill, "Karl Jaspers and Theodor W. Adorno: the metaphysics of the human," History of European Ideas, Volume 31, Issue 1, 2005, pp. 61-84.

[12] Chen Bin, Study on China's Historic Building Art andDigital Virtualization, Mater dissertation, Harbin Engineering University, 2013. 